\title{
May-Thurner syndrome: an uncommon and incidental finding in a postpartum female
}

\author{
Navjot Singh ${ }^{1 \mathrm{EF},}$, Manjot Kaur ${ }^{2 \mathrm{~F}}$, Vivek Jirankali ${ }^{1 \mathrm{~F}}$ \\ ${ }^{1}$ Government Medical College and Hospital, Sector 32, Chandigarh, India \\ 2ESIC Model Hospital, Ramdarbar, Chandigarh, India
}

\section{Abstract}

May-Thurner syndrome or Cockett syndrome is a pathological condition that arises due to extrinsic compression on iliocaval venous territory, leading to venous outflow obstruction. Here, author presents an incidental finding of left common iliac vein extrinsic compression by right common iliac artery with collateral vessels in the pelvis in a postpartum female.

Key words: deep vein thrombosis (DVT), common iliac vein (CIV), common iliac artery (CIA), May-Thurner syndrome (MTS), contrast-enhanced computed tomography (CECT).

\section{Introduction}

Virchow in year 1851, concluded that iliac and femoral deep vein thrombosis (DVT) was five times more prevalent in the left leg than in the right leg. May and Thurner in 1957 explained the biological variation of left common iliac vein (CIV). They discovered vascular wall thickening of left CIV at the point where it was traversed and squeezed by the overlying right common iliac artery (CIA) adjacent to the fifth lumbar vertebra [1]. Fifty per cent luminal narrowing of left CIV due to extrinsic pressure is noted in up to $25 \%$ of normal individuals, but chronic external pressure and pulsation may damage the endothelium of the vessel wall with resultant fibrosis of intima and formation of intraluminal venous webs, and channel spurs with subsequent intraluminal pressure changes proximal and distal to luminal narrowing [2]. This can further give rise to venous hypertension, stenosis, obstruction, and DVT in affected lower extremities $[2,3]$.

\section{Case description}

The study presents a case of a 34-year-old postpartum female with history of left lower limb pain and oedema from the last 3-4 months. There was no history of smoking, and the patient had no symptoms suggestive of pulmonary embolism. Colour Doppler of the left lower limb was performed. It showed patent lumen of deep veins with sluggish blood flow. Contrast-enhanced computed tomography (CECT) scan of the abdomen and pelvis was done to rule out any extrinsic compression or intraluminal thrombus in iliac veins and vena cava. No intraluminal thrombus was noted; however, there was an incidental finding of left $\mathrm{CIV}$ narrowing as it passed under the right CIA adjacent to the fifth lumbar vertebra. Prominent collateral vessels were seen arising from the right internal iliac vein and supplying the left internal iliac and CIV (Figure 1).

\section{Discussion}

May-Thurner syndrome (MTS) or iliac vein compression syndrome is caused due to compression of the left CIV by the right CIA, resulting in increased likelihood of DVT in the left lower limb $[1,4,5]$. The estimated risk of MTS is $2-5 \%$ in patients evaluated for lower limb venous disorders [5]. The mechanisms of narrowing of the left CIV by right CIA are as follows: the first is the anatomical position with resultant physical entrapment of the left CIV,

Correspondence address:

Manjot Kaur, ESIC Model Hospital, \# 92 Tower enclave phase 2, sector A, Jalandhar, Punjab, India, e-mail: rainamanjot42@gmail.com

Authors' contribution:

A Study design · B Data collection · C Statistical analysis · D Data interpretation · E Manuscript preparation · F Literature search · G Funds collection 

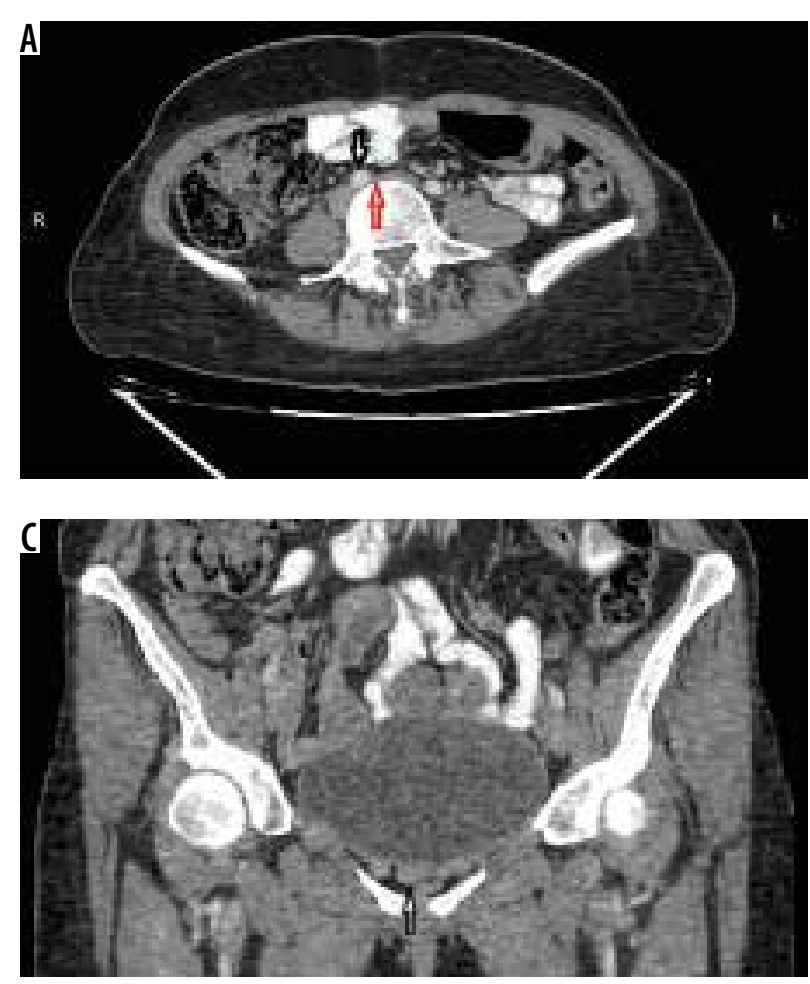

and the second is due to chronic pulsatile compression of the right CIA leading to intimal hypertrophy of the left CIV [6]. MTS is associated with the following:

- female gender, particularly postpartum, multiparous, or using oral contraceptives,

- scoliosis may predispose to MTS due to compression from the lower lumbar vertebra,

- dehydration,

- hypercoagulable disorder,

- cumulative radiation exposure.

These may be directly associated with MTS or may increase the likelihood that asymptomatic MTS will progress to symptomatic MTS [7,8,9-13].

Clinical features of MTS are as follows: acute or chronic unilateral left leg swelling, pain, and skin discoloration. Serious complications include pulmonary embolism, iliac vein rupture, and phlegmasia cerulea dolens [14].

CECT scan is a readily available radiological modality for interpretation of MTS and its accompanying consequences. Venous compression, thrombosis, and collateral vessels are easily visualised on the venous phase of con-

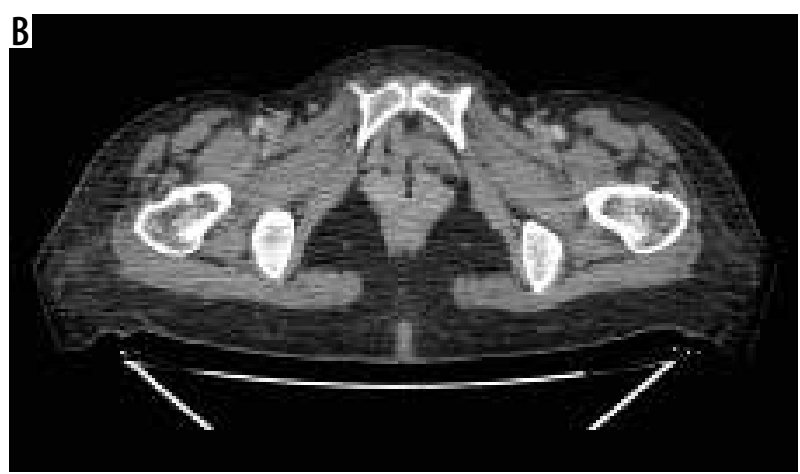

Figure 1. A) Contrast-enhanced computed tomography (CECT) axial scan shows compression of left common iliac vein (red arrow) between right common iliac artery (black arrow) and vertebral body. B) CECT axial and C) coronal scans show venous collaterals (black arrow) in the pelvis posterior to pubic symphysis (axial scan) and inferior to urinary bladder (coronal scan)

trast CT. Lower limb oedema, venous congestion, collateral vessels, and surrounding inflammation are characteristic [2]. After the start of intravenous contrast injection, a scan delay of approximately $90-100$ seconds is advised for excellent enhancement of iliac vessels in the venous phase [15].

\section{Conclusions}

MTS must be taken into differentials in young/middle aged females with unilateral left lower limb pain and swelling. Delay in diagnosis can lead to serious complications like venous thrombosis and pulmonary embolism. CECT is of great importance to diagnose the disease in its early phases because it provides high-quality venous phase images. It can diagnose intravascular thrombus, extrinsic compression by vessel or mass lesion, and collateral formation.

\section{Conflict of interest}

The authors report no conflict of interest.

\section{References}

1. May R, Thurner J. The cause of the predominantly sinistral occurrence of thrombosis of the pelvic veins. Angiology 1957; 8: 419-427.

2. Lugo-Fagundo C, Nance J, Johnson P, Fishman E. May-Thurner syndrome: MDCT findings and clinical correlates. Abdominal Radiology 2016; 41: 2026-2030.

3. Mousa A, AbuRahma A. May-Thurner syndrome: update and review. Ann Vasc Surg 2013; 27: 984-995.
4. Cockett F, Thomas M. The iliac compression syndrome. Br J Surg 1965; 52: 816-821.

5. Taheri S, Williams J, Powell S, et al. Iliocaval compression syndrom. Am J Surg 1987; 154: 169-172.

6. Heniford B, Senler S, Olsofka J, et al. May-Thurner syndrome: management by endovascular surgical techniques. Ann Vasc Surg 1998; 12: $482-486$ 
7. Steinberg J, Jacocks M. May-Thurner syndrome: a previously unreported variant. Ann Vasc Surg 1993; 7: 577-581.

8. Kibbe M, Ujiki M, Goodwin A, et al. Iliac vein compression in an asymptomatic patient population. J Vasc Surg 2004; 39: 937-943.

9. Marston W, Fish D, Unger J, Keagy B. Incidence of and risk factors for iliocaval venous obstruction in patients with active or healed venous leg ulcers. J Vasc Surg 2011; 53: 1303-1308.

10. Patel N, Stookey K, Ketcham D, Cragg A. Endovascular management of acute extensive iliofemoral deep venous thrombosis caused by May-Thurner syndrome. J Vasc Intervention Radiol 2000; 11: 1297-1302.

11. Zander K, Staat B, Galan H. May-Thurner syndrome resulting in acute iliofemoral deep vein thrombosis in the postpartum period. Obstet Gynecol 2008; 111: 565-569.
12. Wax JR, Pinette MG, Rausch D, Cartin A. May-Thurner syndrome complicating pregnancy: a report of four cases. J Reprod Med 2014; 59: 333-336.

13. Murphy E, Davis C, Journeycake J, DeMuth R, Arko F. Symptomatic ileofemoral DVT after onset of oral contraceptive use in women with previously undiagnosed May-Thurner syndrome. J Vasc Surg 2009; 49: 697-703.

14. Kim Y, Ko S, Kim H. Spontaneous rupture of the left common iliac vein associated with May-Thurner syndrome: successful management with surgery and placement of an endovascular stent. Br J Radiol 2007; 80: 176-179.

15. Zucker E, Ganguli S, Ghoshhajra B, Gupta R, Prabhakar A. Imaging of venous compression syndromes. Cardiovasc Diagn Ther 2016; 6: 519-532. 